\title{
EXPERIMENTAL INVESTIGATION AND MECHANISM ANALYSIS: EFFECT OF CONCENTRATION AND TEMPERATURE ON THE VISCOSITY OF NOVEL MWCNT-MUSTARD OIL NANOFLUID
}

\author{
V. VIGNESH ${ }^{a^{*}}$, S. VIJAYAN ${ }^{b}$ AND G. SELVAKUMAR ${ }^{c}$ \\ ${ }^{a}$ Assistant Professor, Department of Mechanical Engineering, St. Mother Theresa Engineering College, Vagaikulam-628103, Fax: +91 4622501007. \\ ${ }^{b}$ Associate Professor, Department of Mechanical Engineering, Sri Sivasubramaniya Nadar College of Engineering, Kalavakkam-603110. \\ ${ }^{c}$ Associate Professor, Department of Mechanical Engineering, Sri Sivasubramaniya Nadar College of Engineering, Kalavakkam-603110.
}

\begin{abstract}
The bio-oils as alternative lubricating fluid are potential solution for the automotive and industrial mechanical systems. The development of novel renewable and non-toxic bio-lubricants with better lubricating distinctiveness will strengthen the economy of farmers in the agricultural based countries. In the present study, different weight fractions of MWCNT-Mustard oil nanofluids are formulated and their possible effects on the dispersion stability and dynamic viscosity are experimentally investigated over the temperatures ranging from 40 to $100^{\circ} \mathrm{C}$. It is observed that the dynamic viscosity and viscosity index of nanofluids were declined with temperature raise, while, it exponentially increased with the raise of MWCNT concentration. The maximum viscosity enhancement of $101.3 \%$ is achieved in comparison to the base fluid at $100^{\circ} \mathrm{C}$. Further, the dynamic viscosity of nanofluids is compared with different classical semi-empirical correlations, however, the remarkable conformities were observed from multilayer feed forward Perceptron (MLP) of artificial neural network (ANN).
\end{abstract}

Keywords: Bio-lubricants; MWCNT; mustard oil; ultrasonication; dynamic viscosity; artificial neural network.

\section{INTRODUCTION}

The emergent concern to curtail the exploit of petroleum derivative mineral oil has led to the exploration for alternative eco-friendly lubricating agents as the mineral oil based lubricants have the lowest biodegradation rate, a high potential for bio-accumulation and toxicity to all organisms. The bio-lubricants degrade faster without bio-accumulation, however, they exhibits considerably high wear rate than mineral oils which limits their industrial applications [1-10]. In general, the bio-oils are vegetable fat which can be produced at industrial scale and are characterized by their fatty acid composition. The amphiphilic nature of biolubricants may provide better lubricating characteristics in both boundary and hydrodynamic regimes [11]. The bio-oil having approximately similar quantity of fatty acids exhibit approximately similar thermo-physical characteristics unless they were refined [8].

In mechanical systems, bio-oils can be used for lubrication when it has acceptable thermo-physical distinctiveness to accomplish the desired role. The viscosity of the bio-lubricants is a significant indicator in separating the contact surfaces and reducing friction which generally thins with increasing temperature [12-13]. It plays a vital role in the categorization of heat transfer equipments in industrial applications and also used to estimate the load carrying capability, Prandtl number ( $\mathrm{Pr}$ ), Reynolds number (Re), flow and thermal behaviors of oil lubricants as well as heat transfer fluids [14]. Among the various bio-oils, mustard oil exhibits superior viscosity index (VI), wear resistance as their triacylglycerol molecules are more polar than mineral based lubricating oils [15] and they are further enhanced by blending distinct amount of nano-scale additives. Poonam et al. (2017) investigated the environmental impacts of mustard oil creation through life cycle approach and reported that the advancement in environmental concern of the agriculture stage can lead to cleaner oil production [16]. Hence, the blending of bio-lubricants with nano-scale additives possess the leeway for formulating novel renewable and non-toxic lubricants with better lubricating distinctiveness and to compete with mineral oil based lubricants technically.

In this study, mustard oil and MWCNT are used for ultrasonically formulating the MWCNT-Mustard oil nanofluids. The SEM (Scanning Electron Microscope) and EDS (Energy-dispersive X-ray spectroscopy) are used for the characterization of MWCNT. The Kinematic viscosity of abundantly as well as commercially available bio-oils is compared and also the kinematic viscosity as well as viscosity index of MWCNT-Mustard oil nanofluid is compared with the bio-oils. The variation of the kinematic viscosity with respect to ultrasonication time at the temperature of $40^{\circ} \mathrm{C}$ is also estimated. Further, the kinematic viscosity of MWCNT-Mustard oil nanofluids is compared with different classical semiempirical correlations as well as ANN multilayer feed forward perceptron for getting remarkable conformities.

\section{MATERIALS AND METHODS}

The wild mustard is a widespread weed of the cultivated lands and its seed has $30-35 \%$ of oil content and triglyceride fatty acids ( $95 \%)$. The wild mustard oil (brassica oil) is extracted from the Indian mustard seeds which can be distinctively cultivated for seeds and their flash, fire and pour points are $329^{\circ} \mathrm{C}$, $340^{\circ} \mathrm{C}$ and $-15.8^{\circ} \mathrm{C}$, respectively. It is used as base oil for coining MWCNTMustard oil nanofluid ( $0.2 \mathrm{wt} \%, 0.4 \mathrm{wt} \%, 0.6 \mathrm{wt} \%, 0.8 \mathrm{wt} \%$ and $1 \mathrm{wt} \%)$ by ultrasonication technique [17-18]. The weight of MWCNT was measured by a precise digital weighing balance (accuracy of $0.01 \mathrm{mg}$ ). The stable MWCNTMustard oil nanofluids are acquired by magnetic stirring (120 min) followed by ultrasonication (45 min). The carbon nanotubes (CNT) such as single-wall carbon nanotubes (SWCNT) and multi-wall carbon nanotubes (MWCNT) are the long straight and parallel carbon layers of cylindrically rolled bulky tubes that received a great consideration since their development due to admirable gas sensing [19], thermal [20], electrical [21], mechanical [22] and tribological [23] distinctiveness. They also widely applied as carriers in therapeutic/detective molecules [24], energy storage [25], electrodes, sensors [26] and nuclear waste management [27]. The morphology of the MWCNT is characterized by SEM and EDS analysis.

Precise assessment of dynamic viscosity is crucial in heat transfer fluid applications in numerous industrial applications. The dynamic viscosity of mustard oil and MWCNT-Mustard oil nanofluids is determined in triplicates by a rotating concentric cylinder type viscometer with temperature bath (OttendorfOkrilla, Germany) for varying the temperature $\left(40-100^{\circ} \mathrm{C}\right)$ [28]. The addition of specific volume of surfactant significantly affects the dynamic viscosity of CNT nanofluids. So, no surfactant was added with the MWCNT-Mustard oil nanofluid during the viscosity measurements [29].

\section{RESULTS AND DISCUSSION}

Figure 1 represents the viscosity of bio-oils such as mustard oil, coconut oil, cotton oil, canola oil, sunflower oil, corn oil, soybean oil and jatropha oil for the temperature ranging from $40-100^{\circ} \mathrm{C}[2,15]$. At $40^{\circ} \mathrm{C}$, the jatropha oil, canola oil and mustard oil exhibits the viscosity of about $43 \mathrm{~mm}^{2} / \mathrm{s}, 40.66 \mathrm{~mm}^{2} / \mathrm{s}$ and 36.61 $\mathrm{mm}^{2} / \mathrm{s}$, respectively thereafter the viscosity of the jatropha oil and canola oil declines excessively than that of mustard oil. The mustard oil exhibits maximum viscosity from $50-100^{\circ} \mathrm{C}$ than other bio-oils presented in the Figure 1 . In $100 \mathrm{~g}$ of wild mustard oil the available saturated, monounsaturated and polyunsaturated fatty acids content are $11.58 \mathrm{~g}, 59.18 \mathrm{~g}$ and $21.23 \mathrm{~g}$, respectively. The monounsaturated fatty acid contents of the bio-oils such as palm oil, soybean oil, peanut oil, rapeseed oil, sunflower oil, maize oil, Canola oil and Grape Seed oil are $39.61 \%, 22.87 \%, 41.19 \%, 63.34 \%, 24.34 \%, 29.74 \%, 57.6 \%$ and $19 \%$, respectively. The higher monounsaturated fatty acid content of mustard oil is the 
reason for the significant viscous characteristics and superior film forming distinctiveness during the measured temperature range.

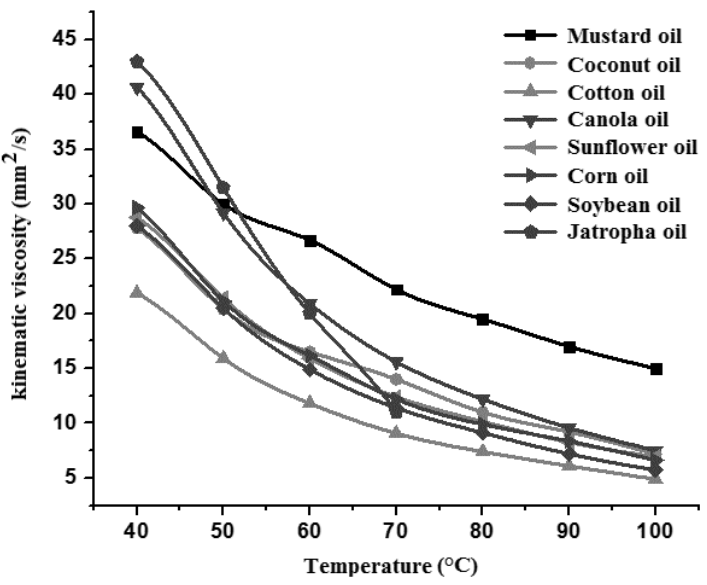

Figure 1. Viscosity of bio-oils.

The viscous characteristics of the mustard oil can be improved by homogeneously dispersing MWCNT ultrasonically. The procured MWCNT (PlasmaChem GmbH, Germany) approximately has 15 walls (thickness: 1 to 4 $\mathrm{nm}$ ), length: $1-10 \mu \mathrm{m}$, Specific surface area: $238 \mathrm{~m}^{2} / \mathrm{g}$ and apparent density of about $200 \mathrm{~g} / \mathrm{cm}^{3}$. Carbon nanotubes $(\mathrm{CNT})$ are the molecular-scale tubes made of honeycomb network graphitic carbon atoms (Graphene) and are seamlessly rolled to form MWCNT. In general, it has low density, high specific surface area and large aspect ratio compared to other nanomaterials. The structure of MWCNT has regular hexagonal lattice on the cylindrical plane. CNTs are insoluble due to their sturdy van der Waals interactions. The densely packed and randomly oriented MWCNT with the diameter is ranging from 80 to $140 \mathrm{~nm}$ with few microns length is observed from its SEM image (Figure 2) and Figure 3 confirms the presence of typical carbon atoms of MWCNT. The agglomeration of MWCNTs is not observed and the tube-walls appear smooth and also have alternately stacked arrangement.

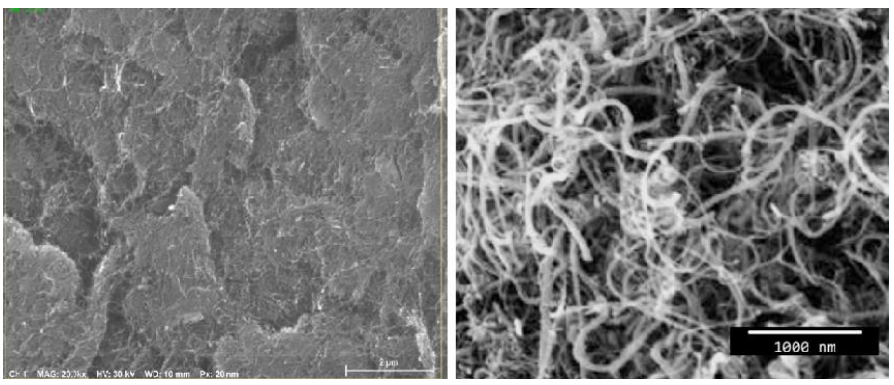

Figure 2. The morphology of MWCNT (SEM image).

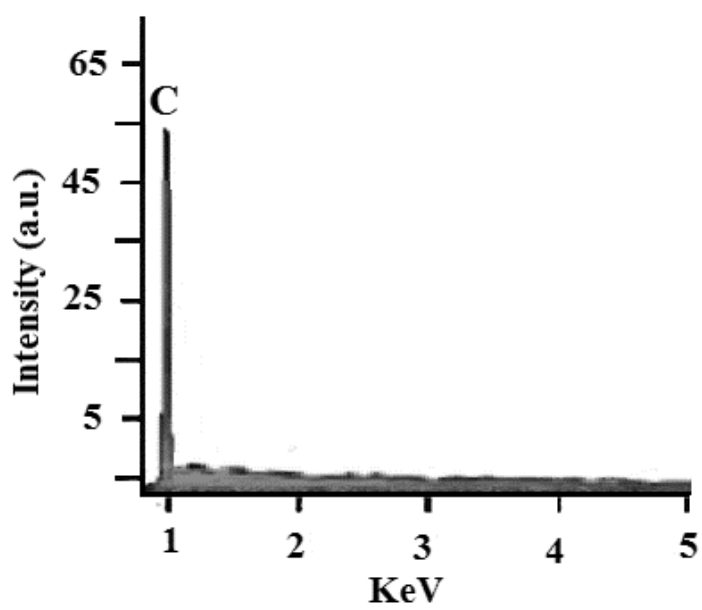

Figure 3. EDS analysis of MWCNT.
The homogeneous suspension of MWCNT-Mustard oil nanofluid was acquired by ultrasonic agitation using a $700 \mathrm{~W}$ probe ultrasonicator. The variation of the kinematic viscosity with respect to ultrasonication time is investigated at the temperature of $40^{\circ} \mathrm{C}$ and presented in the Figure 4 . The rising of the ultrasonication time until $45 \mathrm{~min}$ results in a moderate raise in the dynamic viscosity, and after that, it started to diminish. The ultrasonication breaks down the bulky dispersed nanomaterial clusters to the less intense agglomeration which can be well dispersed in the base fluid.

The aggregation effect of the MWCNT on the dynamic viscosity of MWCNTMustard oil nanofluid lies in multifarious mechanism due to their interparticle reaction. In accordance with Brownian theory, MWCNT in the mustard oil are relentlessly in the faction of collision as well as agglomeration which leads to the formation of aggregate MWCNT structure and accounts for the superior dynamic viscosity. The Brownian motion of the MWCNT in mustard oil is expressed through the Stokes-Einstein diffusion Equation (1) where D', $K_{B}, T, \eta$ and d are the diffusion constant, Boltzmann's constant, absolute temperature, mobility and size of dispersed nanomaterials, respectively. The diffusion constant increases with increasing temperature and nanomaterial weight fractions, hence, the optimum temperature and nanomaterial weight fractions must be estimated to utilize the MWCNT-Mustard oil nanofluid in the suitable industrial applications. The diffusion time $\left(\tau_{\mathrm{D}}\right)$ of the dispersed MWCNT-Mustard nanofluid is determined through the Equation 2 which estimates the time required to travel the distance equal to the size of the dispersed MWCNT in the mustard oil [12].

$$
\begin{aligned}
D^{\prime} & =\frac{K_{B} T}{3 \pi \eta d} \\
\tau_{D} & =\frac{3 \pi \eta d^{3}}{6 K_{B} T} \text { in } \mu s
\end{aligned}
$$

The homogeneous dispersion of regular morphological nanomaterials into the mustard oil intensifies the interparticle reaction and flourishes extensive aggregate structure. Despite, it is an indication of viscosity augmentation which significantly affects the dispersion stability. The exiting literature reveals that the thermo-physical possessions of the nanofluids significantly depend on the geometrical distinctiveness of dispersed nanomaterials [30]. The structure of MWCNT has long straight and parallel carbon layers of cylindrically rolled bulky tubes in regular hexagonal lattice and has sturdy van der Waals interactions.

The few microns length of the MWCNT has less tendency to instigate the aggregate structure than the regular morphological nanomaterials (spherical, cube, etc.). An experimental investigation has been conducted to estimate the dynamic viscosity of MWCNT-Mustard oil nanofluid with the diverse concentrations and temperatures. The data presented in Figure 5 exhibits the average viscosity of MWCNT-Mustard oil nanofluid at diverse temperatures and MWCNT weight fractions when compared with that of pure mustard oil.

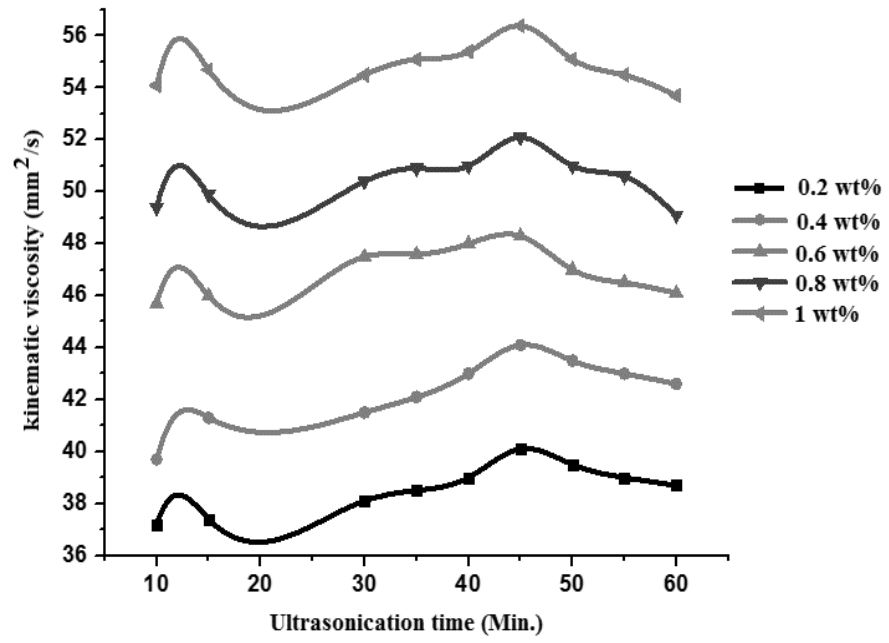

Figure 4. Variations of the kinematic viscosity with respect to ultrasonication time at the temperature of $40^{\circ} \mathrm{C}$. 


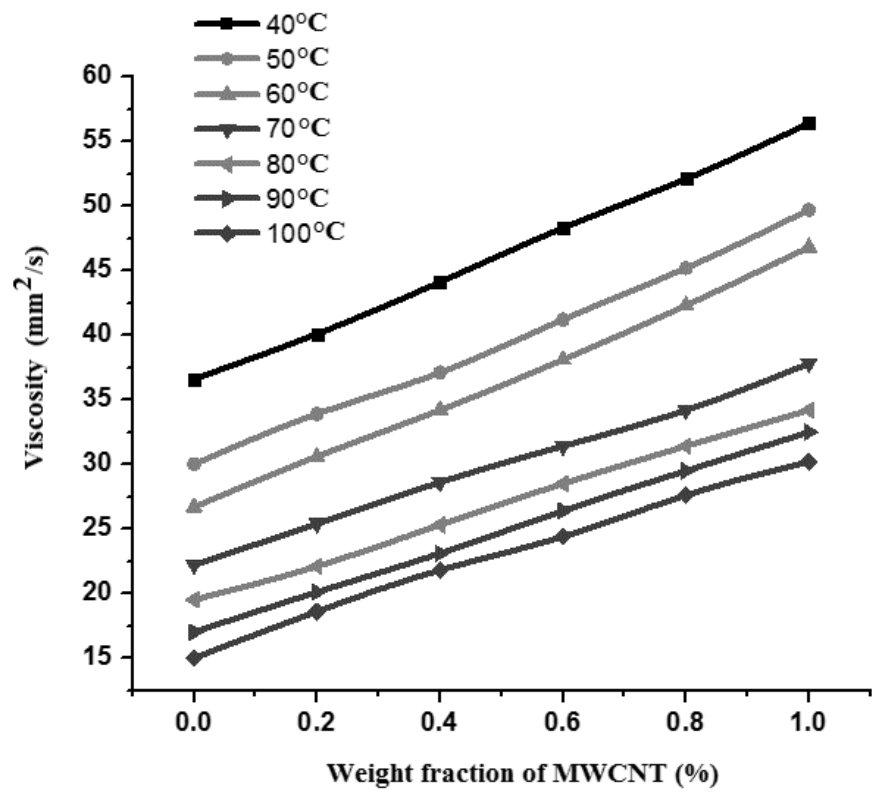

Figure 5. Average viscosity of MWCNT-Mustard oil nanofluid at diverse temperatures.

The MWCNT weight fraction has an astonishing effect on the dynamic viscosity for the temperature ranging from $40-100^{\circ} \mathrm{C}$. It can be pinpointed through the Figure 5 that the dynamic viscosity of MWCNT-Mustard oil nanofluid as well as pure mustard oil for the all temperature diminishes nonlinearly at constant MWCNT weight fraction. The experimental results indicated that when the temperature increases, both MWCNT-Mustard oil nanofluid and mustard oil molecular structure varies momentarily and gradually get aligned at micron dimension. This random motion of molecular structure is less at minimum temperature, therefore, a less resistance in mustard oil/nanofluid or a less reduction in dynamic viscosity exists due to the presence of the homogeneously dispersed MWCNT in the base fluid. The random motion of molecular structure varies with respect to temperature and dispersed MWCNT weigh fraction. It leads to reduction of the inter-molecular forces between mustard oil and dispersed MWCNT surface resulting inferior dynamic viscosity at higher temperature.

The raise of MWCNT weight fraction from 0.2 to $1 \mathrm{wt} \%$ the average dynamic viscosity of the nanofluid raises from 40.10 to $56.4 \mathrm{~mm}^{2} / \mathrm{s}$ at $40^{\circ} \mathrm{C}$ whereas it raises from 30 to $49.7 \mathrm{~mm}^{2} / \mathrm{s}, 26.7$ to $46.8 \mathrm{~mm}^{2} / \mathrm{s}, 22.2$ to $37.8 \mathrm{~mm}^{2} / \mathrm{s}, 19.5$ to $34.2 \mathrm{~mm}^{2} / \mathrm{s}, 17$ to $32.5 \mathrm{~mm}^{2} / \mathrm{s}$ and 15 to $30.2 \mathrm{~mm}^{2} / \mathrm{s}$ at the temperatures of $40^{\circ} \mathrm{C}$, $50^{\circ} \mathrm{C}, 60^{\circ} \mathrm{C}, 70^{\circ} \mathrm{C}, 80^{\circ} \mathrm{C}, 90^{\circ} \mathrm{C}$ and $100^{\circ} \mathrm{C}$, respectively. It clearly designates that with the raise in temperature the dynamic viscosity of nanofluid diminishes considerably. Moreover, with the raise of MWCNT weight fraction from 0.2 to $1 \mathrm{wt} \%$ the average dynamic viscosity of the nanofluid rises from 15 to $30.2 \mathrm{~mm}^{2} / \mathrm{s}$ at $100^{\circ} \mathrm{C}$. The increased weight fraction of MWCNT in the mustard oil increased, the relative resistance against the molecular structure movements also increased. Hence, dynamic viscosity of MWCNT-Mustard oil is improved with the raise of nanomaterial weight fraction. Nevertheless, the monounsaturated fatty acid molecule of the MWCNT-Mustard oil nanofluid gets detached from their triglycerides compound and forms as free radicals which weak bond between the molecules due to the reduced like London forces and Vander Vaal's forces. It is the reason for the dynamic viscosity reduction of nanofluids at high temperatures.

Figure 6 demonstrates the consequences of MWCNT weigh fraction and temperature on relative viscosity (quotient of dynamic viscosity of MWCNT nanofluid to that of mustard oil. The relative viscosity for the all MWCNT weight fraction confers beyond unity and discloses that relative viscosity factor enhances with the rise of MWCNT weight fraction. The relative viscosity of MWCNTMustard oil nanofluids at $40^{\circ} \mathrm{C}$ temperature is observed as 1.09 for $0.2 \mathrm{wt} \%, 1.2$ for $0.4 \mathrm{wt} \%, 1.32$ for $0.6 \mathrm{wt} \%, 1.42$ for $0.8 \mathrm{wt} \%, 1.54$ for $1 \mathrm{wt} \%$ of solid volume fraction, respectively whereas at $70^{\circ} \mathrm{C}$ temperature it is observed as 1.14 for 0.2 wt $\%, 1.29$ for $0.4 \mathrm{wt} \%, 1.41$ for $0.6 \mathrm{wt} \%, 1.54$ for $0.8 \mathrm{wt} \%, 1.70$ for $1 \mathrm{wt} \%$ of solid volume fraction, respectively. Similar, for the high temperature of $100^{\circ} \mathrm{C}$, relative viscosity it is observed as 1.24 for $0.2 \mathrm{wt} \%, 1.45$ for $0.4 \mathrm{wt} \%, 1.62$ for $0.6 \mathrm{wt} \%, 1.84$ for $0.8 \mathrm{wt} \%, 2.01$ for $1 \mathrm{wt} \%$ of solid volume fraction, respectively.
The percentage augmentation in the dynamic viscosity is also estimated by using the Equation 3 and observed that hat the enhancement percentage is rising with the raise in MWCNT weight fraction where the greatest enhancement is observed for the highest weight fraction $(1 \mathrm{wt} \%)$ at $100^{\circ} \mathrm{C}$ [30]. The squat weight fraction of MWCNT-Mustard oil nanofluids does not contribute greatly to the dynamic viscosity augmentation. At $40^{\circ} \mathrm{C}, 50^{\circ} \mathrm{C}, 60^{\circ} \mathrm{C}, 70^{\circ} \mathrm{C}, 80^{\circ} \mathrm{C}$ and $90^{\circ} \mathrm{C}$ the greatest dynamic viscosity augmentation is approximately found to be $54 \%$, $65.6 \%, 75.2 \%, 70.2 \%, 75.3 \%$ and $91.1 \%$, respectively for $1 \mathrm{wt} \%$ of nanofluid and the augmentation is reduced to $9.5 \%, 13 \%, 14.6 \%, 14.4 \%, 13.3 \%, 18.21 \%$ and $24 \%$ for $0.2 \mathrm{wt} \%$ of nanofluid. Further, the dynamic viscosity-temperature behavior of nanofluid is characterized through the arbitrary VI. The VI (ASTM D2270) of the mustard oil and different weight fractions of MWCNT-Mustard oil nanofluid designates the extents of thickness, or resistance to flow with temperature changes. It is estimated through Equation 4 in which $\mathrm{U}$ indicates the viscosity value at $40^{\circ} \mathrm{C}, \mathrm{L}$ and $\mathrm{H}$ are values are based on the kinematic viscosity at $100^{\circ} \mathrm{C}$ for oils of VI 0 and 100 respectively [30]. The Figure 7 clearly depicts the VI of the commercially available bio-oils and different weight fractions of MWCNT-Mustard oil nanofluids estimated from the viscosity measured at $40^{\circ} \mathrm{C}$ and $100^{\circ} \mathrm{C}$. The VI of the additive free bio-oils is found to be lower than those of MWCNT-Mustard oil nanofluids in which $1 \mathrm{wt} \%$ of MWCNT depicts maximum VI value.

$$
\begin{aligned}
& \text { Viscosity enhancement }(\%)=\left(\frac{\mu_{n f}}{\mu_{b f}}-1\right) \times 100 \\
& \text { Viscosity index }(V I)=\frac{L-U}{L-H}
\end{aligned}
$$

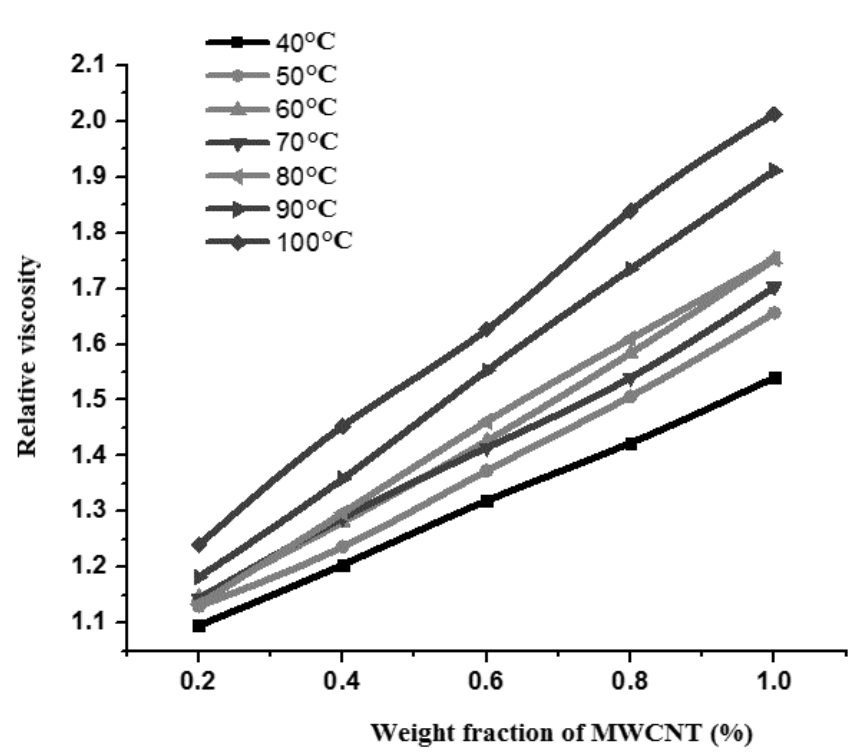

Figure 6. Relative viscosity of MWCNT-Mustard oil nanofluid at diverse temperatures.

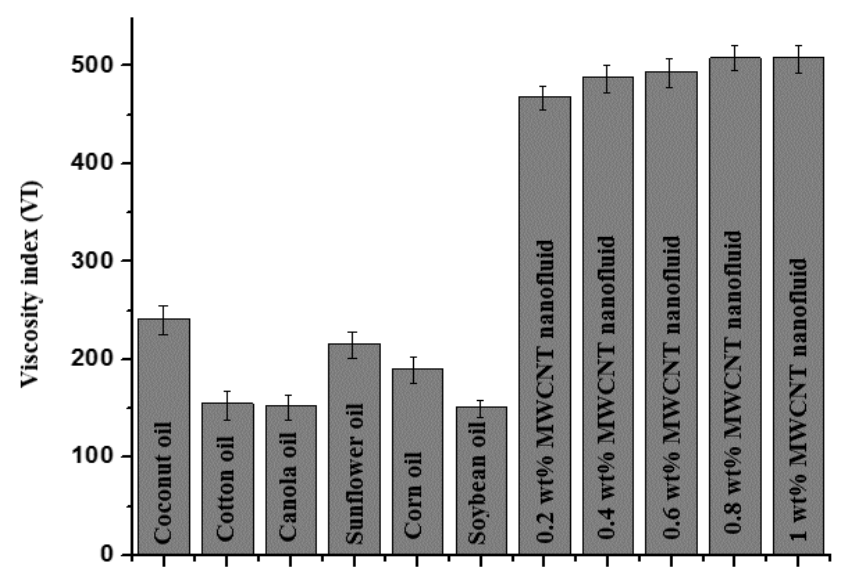

Bio-oils and MWCNT-Mustard oil nanofluids

Figure 7. VI of bio-oils and MWCNT-Mustard oil nanofluids. 
Over the last two decades, experimental and theoretical data interpretations were performed to evaluate how the dispersion of nanomaterials with base fluids affects the dynamic viscosity. Einstein (1906) reported a classical correlation (Equation 5) to calculate the dynamic viscosity of nanofluids $(\varnothing<0.02)$ which mostly underestimates due to linear property [31]. Krieger and Dougherty (1959) modified the Einstein's classical correlation and reported a semi-empirical correlation (Equation 6) by considering volume fraction of nanomaterials and the effective viscosity [32]. Brinkman (1952) (Equation 7) [33], Nielsen (1970) (Equation 8) [34], Batchelor (1977) (Equation 9) [35], Tseng \& Lin (2003) (Equation 10) [36], Maiga (2004) (Equation 11) [37], Chen et al. (2007) (Equation 12) [38], Nguyen (2008) (Equation 13) [39] and Abedian \& kachanow (2010) (Equation 14) [40] proposed their comprehensive model to estimate the dynamic viscosity of nanofluids. These semi-empirical model correlations have limitations because the most influencing parameters like temperature and interaction between the nanomaterials were substantially ignored. Nguyen $e t$ al. (2008) proposed a semi-empirical correlation (Equation 15) without considering the nanomaterial concentration to estimate the dynamic viscosity of nanofluids [39]. Harandi et al. (2016) (Equation 16) [41], Sundar et al. (2016) (Equation 17) [42], Akbari et al. (2017) (Equation 18) [43], Alrashed et al. (2018) (Equation 19) [44], Asadi et al. (2018) (Equation 20) [45], Ghasemi et al. (2018) (Equation 21) [46] and Karimipour et al. (2018) (Equation 22) [47] proposed their correlations by considering the nanomaterial concentration and temperature to estimate the dynamic viscosity of nanofluids.

$$
\begin{aligned}
& \mu_{\text {nf }}=\mu_{\text {bf }}(1+2.5 \varnothing) \\
& \mu_{n f}=\mu_{b f}\left(1+\frac{\varphi}{12.5}\right)^{6.356} \\
& \mu_{\mathrm{nf}}=\mu_{\mathrm{bf}}(1-\emptyset)^{2.5} \\
& \mu_{n f}=\mu_{b f}(1+1.5 \phi) e^{\frac{\varphi}{1-\varphi m}} \\
& \mu_{\mathrm{nf}}=\mu_{\mathrm{bf}}\left(1+2.5 \varnothing+6.5 \emptyset^{2}\right) \\
& \mu_{n f}=\mu_{b f} 13.47 e^{35.98 \varphi} \\
& \mu_{\mathrm{nf}}=\mu_{\mathrm{bf}}\left(1+7.23 \emptyset+123 \emptyset^{2}\right) \\
& \mu_{\mathrm{nf}}=\mu_{\mathrm{bf}}\left(1+10.6 \varnothing+10.6 \emptyset^{2}\right) \\
& \mu_{\text {nf }}=\mu_{\text {bf }} 0.904 \mathrm{e}^{0.1483 \varnothing} \\
& \mu_{n f}=\mu_{b f}\left(\frac{1}{1-2.5 \varphi}\right) \\
& \mu_{n f}=\mu_{b f}\left(2.1275-0.0215 T+0.00027 T^{2}\right) \\
& \mu_{n f}=\mu_{b f}\left(1+0.0162 \phi^{0.7038} T^{-0.6009}\right) \\
& \mu_{n f}=0.0162 \mu_{b f}(1+\phi)^{0.6556} \\
& \mu_{n f}=\mu_{b f}\left(-24.81+3.23 T^{0.08014} \exp \left(1.838 \phi^{0.002334}\right)-0.0006779 T^{2}+0.024 \phi^{3}\right) \\
& \mu_{n f}=\mu_{b f}\left(233.2713 \phi^{0.8623}\left(\frac{1}{T}\right)^{0.8263}-2.6698 \phi^{0.4821}+0.9145\right) \\
& \mu_{n f}=\mu_{b f}\left(1604+256.8 \varphi+24.73 \phi^{3}+1.615 T^{2}+0.07343 \varphi T^{2}+83.2 \mathrm{~T}-7.389\right. \\
& \mathrm{T} \phi-0.01123 T^{3}-74.19 \phi^{2} \\
& \mu_{n f}=\mu_{b f}\left(-1.735 T^{-0.017}-0.027 \phi^{0.418}+0.039 \phi^{1.543} T^{-0.033}+2.956\right) \\
& \mu_{n f}=\mu_{b f}\left(43947802.6097 \phi^{3.3239}\left(\frac{1}{T}\right)^{1.2107}+22.755\left(\frac{1}{T}\right)^{0.5891}-0.9317\right)
\end{aligned}
$$

To ensure the aptness of above theoretical correlations on MWCNT-Mustard oil nanofluid, the dynamic viscosity values are estimated using the Equations 522 and are compared with the experimental dynamic viscosity data. The experimental dynamic viscosity data are not precisely same as the theoretically estimated data in which the data estimated by the theoretical correlations of Ghasemi $e t a l$. and Krieger \& Dougherty are closer to the experimental dynamic viscosity data only at minimum weight fraction $(0.2 \mathrm{wt} \%)$ of the MWCNT dispersion in the mustard oil. An excessive digression is observed among the theoretical prophecy and the experimental data. On the whole, the dynamic viscosity predicted by the theoretical correlations is greatly inferior to the experimental dynamic viscosity of MWCNT-Mustard oil nanofluids. Moreover, these viscosity determinations through laboratories at different temperatures and nanomaterial concentrations are quite expensive and time-consuming.

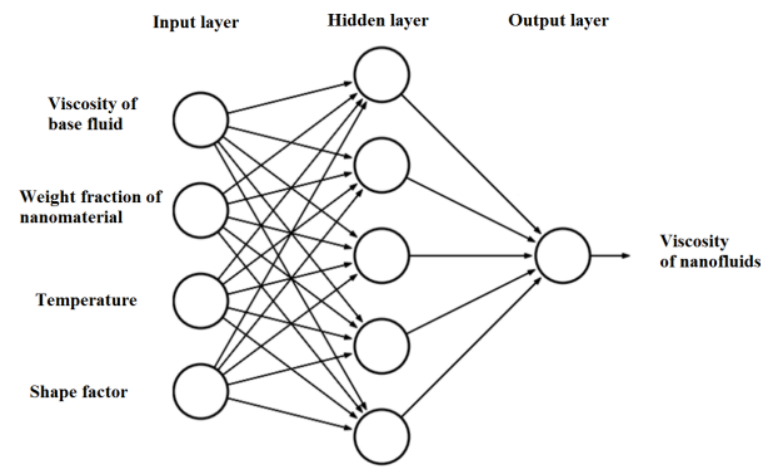

Figure 8. ANN multilayer perceptron.
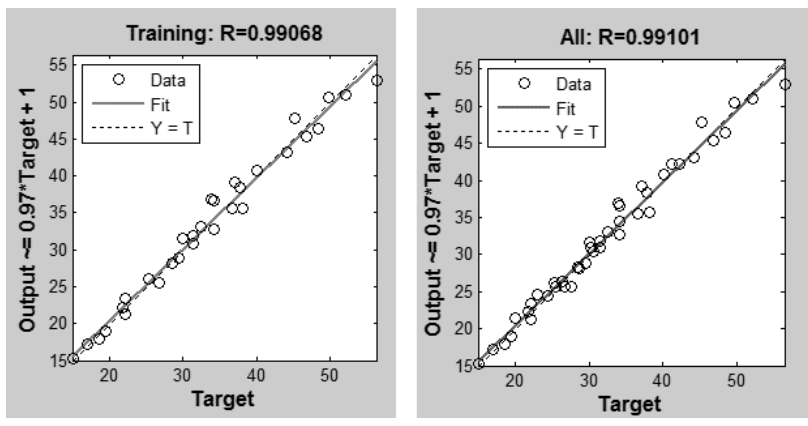

Figure 9. Approximation of dynamic viscosity of nanofluids through ANN

The soft computing method like artificial neural networks (ANN) and curve fitting and mathematical modeling are avoids the cost of experimental investigations while analyzing thermo-physical distinctiveness of nanofluids in which the ANN estimations can precisely envisage the dynamic nanofluids subjected to different concentrations, temperature, shape and size. The multilayer perceptron is a class of feed forward ANN has the ability to decipher the extremely complex problems stochastically than the Single-layer perceptron. The typical architecture of the multilayer perceptron feed forward ANN has input layer (viscosity of base fluids, weight fraction of MWCNT, temperature and shape factor), output layer (dynamic viscosity of MWCNT-Mustard oil nanofluid) and hidden layer (hidden neurons) as presented in the Figure 8. The training data fed into the ANN for learning the rapport between inputs and output distinctiveness in which sigmoid functions are used in the learning algorithms. The effectiveness of ANN prediction is calculated by the Root Mean Squared Error and the divergence between the experimental and the data estimated by the multilayer perceptron feed forward ANN. The Approximated dynamic viscosity of nanofluids through ANN is presented in the Figure 9. The relationship between the investigational and estimated dynamic viscosity data points lie within $5 \%$ difference.

\section{CONCLUSIONS}

The bio-lubricants exhibit superior biodegradability and significantly squat toxicity than the mineral based lubricating oils, hence, this study helps to utilize the MWCNT-Mustard oil nanofluid in the suitable industrial applications. Despite the bio-lubricants are biodegradable, it is prone to endure several chemical reactions when it is exposed to heat/light. Suitable antioxidants must be added with the bio-lubricants to thwart such occurrence which also enhances its shelf life. Hence, the blending of bio-lubricants with nano-scale additives possess the leeway for formulating novel renewable and non-toxic lubricants with better lubricating distinctiveness and to compete with mineral oil based lubricants technically.

\section{REFERENCES}

1. Y. Wang, C. Li, Y. Zhang, B. Li, M. Yang, X. Zhang, J. Manuf. Proc. 26, 94, (2017).

2. E.E.G. Rojas, J.S.R. Coimbra, J.T. Romero, Int. J. Food Prop. 16, 1620, (2013).

3. K.M. Kumar, A. Ghosh, J. Mater. Process. Tech. 237, 55, (2016).

4. S.V. Sujith, A.K. Solanki, R.S. Mulik, J. Mol. Liq. 286, 110905 (2019). 
5. M. Shahabuddin, H.H. Masjuki, M.A. Kalam, M.M.K. Bhuiya, H. Mehat, Ind. Crops Prod. 47, 323, (2013).

6. S. Rani, M.L, Joy, K.P. Nair, Ind. Crops Prod. 65, 328, (2015).

7. S. Guo, C. Li, Y. Zhang, Y. Wang, B. Li, M. Yang, X. Zhang, G. Liu, J. Clean. Prod. 140, 1060, (2017).

8. J.F. Hoffmann, J.F. Henry, G. Vaitilingom, R. Olives, M. Chirtoc, D. Caron, X. Py, Int. J. Therm. Sci. 107, 105, (2016).

9. K.M. Arvind, V. Ajitanshu, Fuel 214, 386 (2018).

10. A.R.M. Kumar, M. Kannan, G. Nataraj, Renew. Energy, 146, 1781, (2020).

11. R.D. Kulkarni, P.S. Deshpande, S.U. Mahajan, P.P. Mahulikar, Ind. Crops Prod. 49, 586, (2013).

12. J. Sunil, R. Maheswaran, 'Relative antiwear property studies on nano garnet SN500 gear lubricant', Lambert Academic Publications, Germany, 2018.

13. J. Sunil, R. Maheswaran and V.G. Anisha, Enhancement of thermal conductivity using nanofluids, Lambert Academic Publications, Germany, 2018.

14. K. Poonam, J. Suresh, P. Suneel, J. Clean. Prod.166, 988, (2017).

15. F. Aladedunye, R. Przybylski, Food Chem. 141(3), 2373, (2013).

16. R. Kreivaitis, J. Padgurskas, M. Gumbyte, V. Makareviciene, B. Spruogis, Transport 26(2), 121, (2011).

17. S.B. Naghadeh, S. Vahdatifar, Y. Mortazavi, A. Khodadadi, A. Abbasi, Sensor. Actuat. B-Chem. 223, 252, (2016).

18. A. Miranda, N. Barekar, B.J. McKay, J. Alloy. Compound. 774, 820, (2019).

19. N. Forintos, T. Czigany, Compos. B: Eng. 162, 331, (2019).

20. C. Zeng, C. Lin, J. Zhang, J. Liu, G. He, Y. Li, Compos. Sci. Technol. 184, 107842, (2019).

21. Y. Liad, Q. Wang, S. Wang, Compos. Part B: Eng. 160, 348, (2019).

22. J. Meng, X. Li, C. Wang, H. Guo, J. Liu, H. Xu, ACS Appl. Mat. Interfac. 7, 3180, (2015.

23. K.K. Gangu, S. Maddilaa, S.B. Mukkamala, S.B. Jonnalagadda, J. Energy Chem. 30, 132, (2019).
24. J. Huang, S. Her, X.X. Yang, M. Zhi, Nanomaterial. 8, 786, (2018).

25. A. Sengupta, N.K. Gupta, J. Environ. Chem. Eng. 5(5), 5099, (2017).

26. M.S. Sisodia, D.K. Rajak, A.K. Pathak, C. Guria, J. Petrol. Sci. Eng. 125, 247, (2015).

27. G. Teng, L. Changhe, Z. Yanbin, Y. Min, J. Dongzhou, J. Tan, H. Yali, L. Runze, Tribol. Int. 131, 51, (2019).

28. A.N. Omrani, E. Esmaeilzadeh, M. Jafari, A. Behzadmehr, Diam. Relat. Mater. 93, 96, (2019).

29. A. Einstein, Ann. Phys. 324, 289 (1906).

30. I.M. Krieger, T.J. Dougherty, Trans. Soc. Rheol. 3, 137, (1959).

31. H. Brinkman, J. Chem. Phys. 20, 571, (1952).

32. L.E. Nielsen, J. Appl. Phys. 41, 4626, (1970).

33. Batchelor, J. Fluid Mech. 83, 97, (1977).

34. W.J. Tseng, K.C. Lin, Mater. Sci. Eng. A. 355(1-2), 186, (2003).

35. S.E.B. Maiga, C.T. Nguyen, N. Galanis, G. Roy, Superlattice. Microst. 35, $543,(2004)$.

36. H. Chen, Y. Ding, C. Tan, New J. Phys. 9, 367, (2007).

37. C.T. Nguyen, F. Desgranges, N. Galanis, Int. J. Therm. Sci. 2, 103, (2008).

38. B. Abedian, M. Kachanov, Int. J. Eng. Sci. 48, 962, (2010).

39. Harandi, S. Sarbolookzadeh, A. Karimipour, M. Afrand, M. Akbari, Int. Commun. Heat and Mass Tran. 76, 171, (2016).

40. L. Sundar, G.O. Syam, E.V.R. Irurueta, M.K. Singh, A.C.M. Sousa, Case Stud. Therm. Eng. 7, 66, (2016).

41. M. Akbari, M. Afrand, A. Arshi, A. Karimipour, J Mol Liq. 233, 352, (2017).

42. A.A.A. Alrashed, A. Karimipour, S.A. Bagherzadeh, M.R. Safaei, M. Afrand, Int. J. Heat Mass Trans. 127, 925, (2018).

43. A. Asadi, M. Asadi, A. Rezaniakolaei, L.A. Rosendahl, S. Wongwises, Appl. Therm. Eng. 129, 577 (2018)

44. S. Ghasemi, A. Karimipour, Appl. Therm. Eng. 138, 189, (2018).

45. A. Karimipour S.A. Bagherzadeh, M. Goodarzi, Int. J .Heat Mass Trans. 127, 1169, (2018). 